\section{Mapping Rwanda public health research(1975-2014)}

Brice Poreau

Institut Santé Publique Relations Internationales (ISPRI) / International Studies Public Health Institute (ISPHI) Rue E. Pons 69004 Lyon - France poreau_brice@yahoo.fr Fax : +33 456520752 Tel: +33 456520753

\section{Abstract}

Background: Since the genocide occurred in 1994, Rwanda has faced up to the challenge of rebuilding. Public health is a main field to understand this rebuilding.

Objectives: In this paper, the aim was to map the scientific research on public health in Rwanda after the genocide and to present the links between different financing systems.

Methods: We used bibliographic analyses with Web of Science of papers published during the period 1975-2014. We performed analyses on journals, most cited articles, authors, publication years, organizations, funding companies, countries, and keywords.

Results: We obtained 86 articles between 1975 and 2014. Most articles were published after 2007. The main countries of research laboratories were the United States of America, Rwanda, England and Belgium and represented the main network collaboration. The relevant keywords were: HIV, woman, child, program, rural and violence.

Conclusions: Public health research on Rwanda appeared 14 years after the genocide. A main field was emerging: the spread Conclusions: Public health research on Rwanda appeared 14 years after the genocide. A main field was emerging: the spread
of HIV with mother-child transmission, and the policies to take this subject into account in rural zones. The network of of HIV with mother-child transmission, and the policies
institutions developing these studies was USA-Rwanda.

Keywords: Rwanda; Public health; HIV; woman; social network analysis; bibliometrics

DOI: http://dx.doi.org/10.4314/ahs.v14i4.41

\section{Introduction}

Twenty years ago, between 800000 and 1200000 people perished according to historical references ${ }^{1}$. In few months, ethnic mass slaughters occurred in all parts of the country.The rebuilding has remained incomplete because of the gigantic tasks in different areas. One of the major areas is public health. In fact, public health represented the needs and demands about population ${ }^{2}$. In low-income countries, public health systems were not suitable to population need; therefore, after genocide and the efforts to rebuild the healthcare structures, the task seemed a major one ${ }^{3}$. Public health covered different fields such as infectiology ${ }^{4}$, parasitology $y^{5}$, mental health ${ }^{6}$, organization of the centers and financing movements?

\section{Corresponding author:}

Brice Poreau

Institut Santé Publique Relations

Internationales (ISPRI)/International

Studies Public Health Institute (ISPHI)

Rue E. Pons 69004 Lyon-France

poreau_brice@yahoo.fr

Fax : +33 456520752 Tel: +33456520753
After 2008, the World Health Organization presented several programs on public health in Rwanda ${ }^{8}$. After 2010, the main objectives were the fight against HIV, tuberculosis and malaria, the fight against the transmission mother-child ${ }^{8}$, corresponding to the Millennium Development Goals ${ }^{46}$.

The aim of this article was to analyze the advancement of scientific publications on public health in Rwanda during the period 1975-2014, and to present the knowledge structures of public health researchers in the world compared to the social situation of Rwanda.

\section{Methods}

We used the Science Citation Index-Expanded (SCIE) database, accessed through the Web of Science (WOS) platform from Thomson Reuters. In the advanced search, we obtained the articles by this formula: TS=(public health AND Rwanda). We verified each record to ensure their relevance. The period was1975 2014. The aim was to see any differences before and after genocide (occurred in 1994). Moreover, no restrictions were performed concerning the document types. Then, we performed the "analysis results" function of WOS. We extracted: journals, most cited articles, au- thors, countries, funding agencies, organizations, publication years.

In order to evaluate the research networks between countries, after the analysis by country, we reviewed records of each country and then performed the analysis a second time in order to know the links between the chosen country and the other countries. We then established the diagram.

Table 1: records per year from 1991 (first publication) to 2014 . $72 \%$ of publications were after 2007.

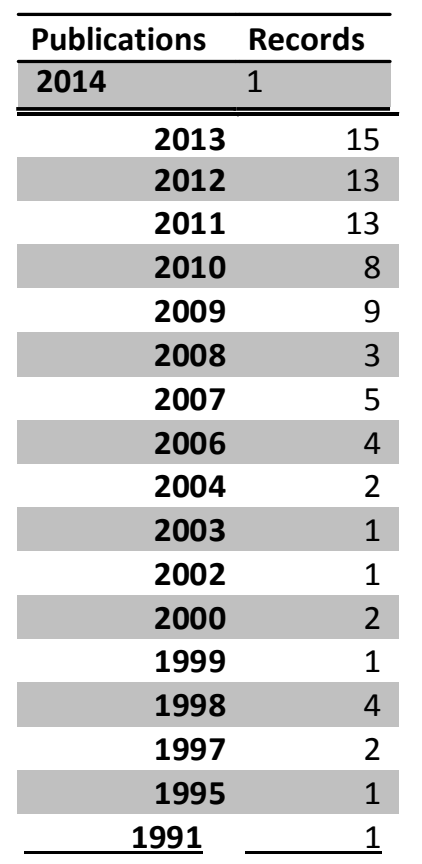

The three authors with most records were Binag- cited records were from Leroy et al., Mann et al waho, Karema and Ngabo with only Binagwaho first and Otten et al. ${ }^{412-13}$. tions. The main journals were The Bulletin of WHO (7/86), AIDS $(5 / 80)$, BMC Health services reserch (3/86) and BMC public Health (3/86). The three most rord (KW) researches to get the main relevant topics. These analyses are to compare with former bibliometric studies in ther fields ${ }^{9-11}$

(a) 86 records. Only one publication was be1994 (table1). 62/86 (72\%) were after 2007 (table1). 
Table 2: funding agencies (68) from European, US or Asian regions, a small part were form Rwanda with the Ministry of Health and the National Rwanda University and the United States of America with Harvard University

Table 2: funding agencies (68) from European, US or Asian regions, a small part were form Rwandan institutions.

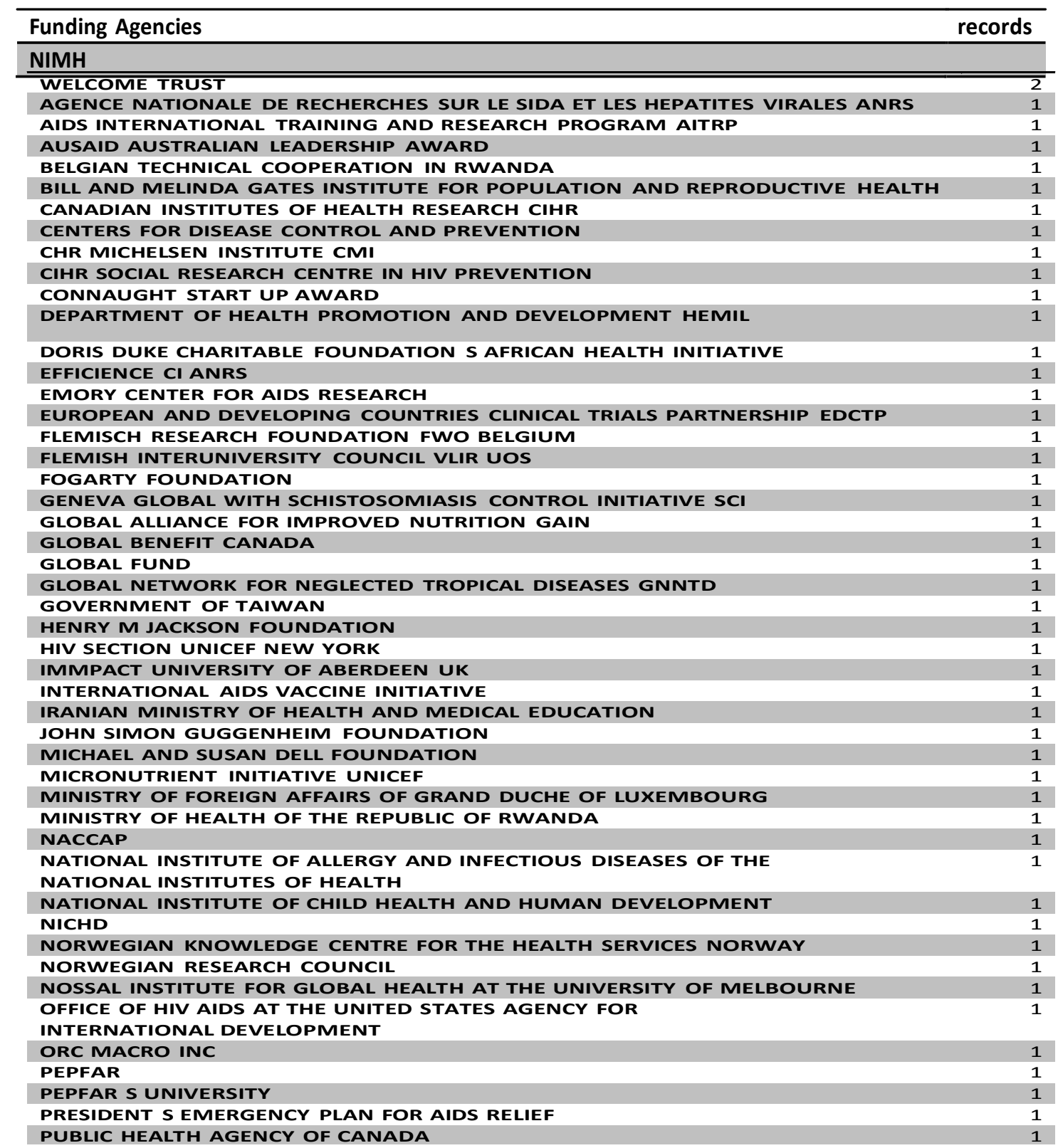

were the most two represented with 24/86 for Rwanda We developed the networks between the main countrie institutions and more than 30 for the USA (table 3). (diagram 1). The scientific network on Rwanda public The ten main countries were the United States of health research with the main countries involved is deAmerica (41/86), Rwanda (33/86), England (15/10), scribed. The main arrow is between the USA and RwanBelgium (10/86), Switzerland (9/86), France (7/86), da (with 41 records on 86). This is the most important Australia (5/86), Canada (5/86), Kenya (5/86) and the cooperation. The second most important collaboration Netherlands (5/86). is between Rwanda and Belgium (8/86 articles). Finally,
Table 3: Main institutions, references from Rwandan institutions were a large part and US institutions were well represented.

\begin{tabular}{lc}
\multicolumn{1}{c}{ Organizations } & records \\
\hline HARVARD UNIV & 11 \\
\hline MINIST HLTH & 8 \\
\hline NATL UNIV RWANDA & 8 \\
\hline INST TROP MED & 6 \\
\hline COLUMBIA UNIV & 5 \\
BRIGHAM WOMENS HOSP & 4 \\
\hline WORLD BANK & 4 \\
\hline ACCESS PROJECT & 3 \\
\hline DARTMOUTH CTR HLTH CARE DELIVERY SCI & 3 \\
\hline LONDON SCH HYG TROP MED & 3 \\
\hline PARTNERS HLTH & 3 \\
\hline PARTNERS HLTH INSHUTI MU BUZIMA & 3 \\
\hline RWANDA BIOMED CTR & 3 \\
\hline UNIV AMSTERDAM & 3 \\
\hline UNIV BORDEAUX 2 & 3 \\
UNIV MARYLAND & 3 \\
\hline UNIV N CAROLINA & 3 \\
UPPSALA UNIV & 3 \\
WHO & 3 \\
\hline ABT ASSOCIATES INC & 2 \\
\hline AUSTRALIAN NATL UNIV & 2 \\
\hline CTR HOSP UNIV KIGALI & 2 \\
\hline EMORY UNIV & 2 \\
\hline GLOBAL HLTH DELIVERY PARTNERSHIP & 2 \\
\hline HEALTHNET INT & 2 \\
\hline
\end{tabular}

the diagram illustrates four other networks: Rwanda- USA (4/86) and Netherlands-Rwanda (4/86). The Switzerland (4/86), Switzerland-USA(5/86), England- last networks are less important (less than 4 records on 86). 


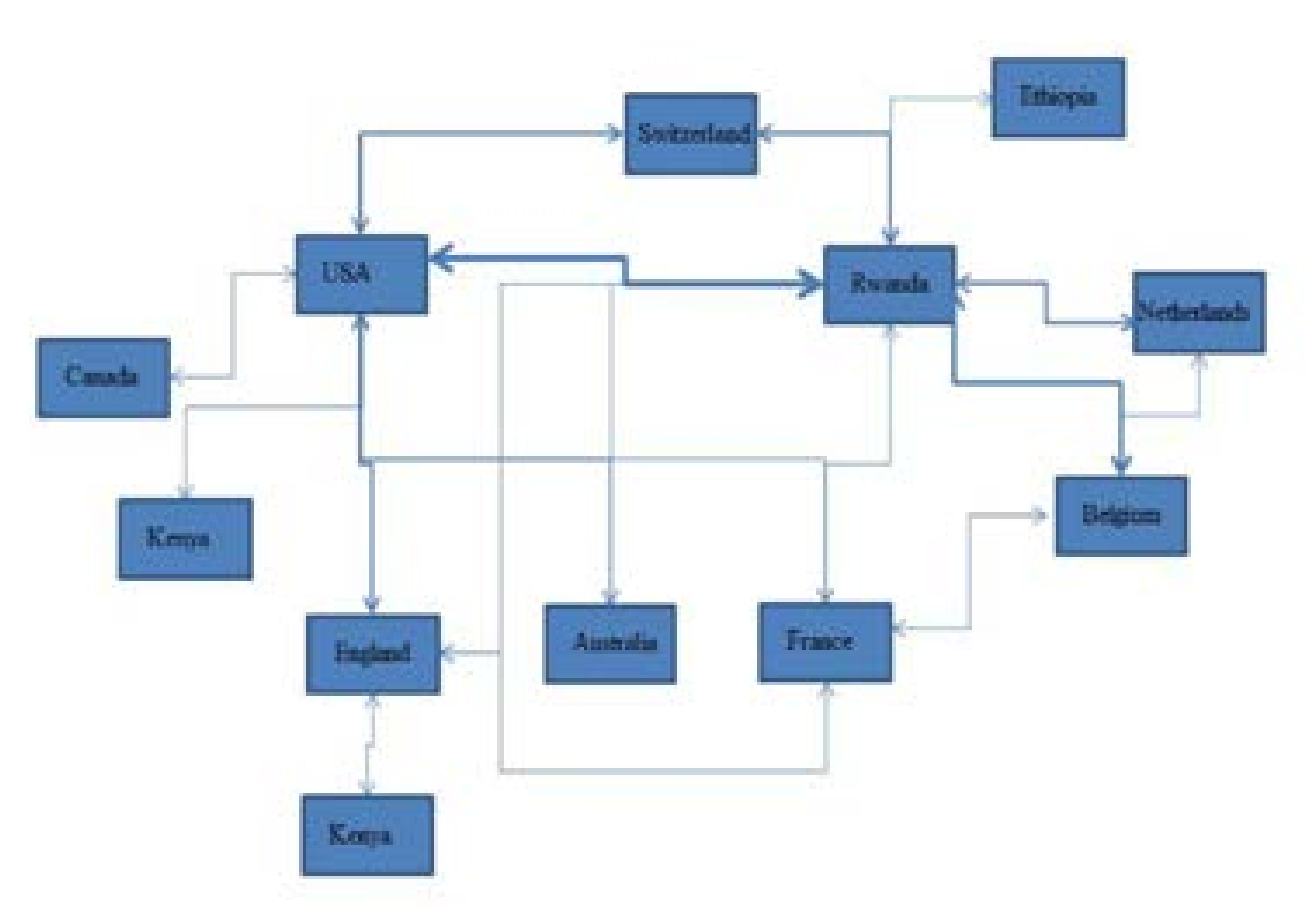

There are three main groups: the first and most important is the USA (with 41 records on 86). Then, the to Millenium development Goals 4 to 6 are showing an second group is Belgium (8/86 articles). The third increasing dominance in publication.

important group is between: Rwanda-Switzerland, Switzerland-USA, England-USA and NetherlandsRwanda.

On an international political point of view, this period of publications corresponds to the programs launched by the World Health Organization ${ }^{8}$. Moreover, it correKeyword analysis revealed the terms woman (wom- sponds to a major involvement of the government. The
en) for $29 / 86$ records, program(s) $30 / 86$ records, year 2012 was significant with advertising on the need HIV 24/86 records, child (children, childhood) $21 / 86$ to prevent several diseases ${ }^{16}$. International financing records, rural 17/86, violence 12/86, sex 12/86.

\section{Discussion}

According to our analysis, only one study was published before $1994^{14}$. It deals with the economic cost of malaria in Rwanda. Article on the same subject was published after $2007^{15}$ and corresponded to the Millennium Developmental Goal 6 (combat HIV/AIDS, malaria and other diseases). Nevertheless, most of the records were after 2007. It has taken more than one

decade after genocide to see interest in Rwandan public health. Moreover, the last few years (from 2010 up to now) are the most relevant for publichealth studies. The limitations on publishing and research cannot be
only attributed to genocide. Because only one study was published before genocide, it means that structures concerning public health were not created before 1994. The genocide didn't allowed researches to create these structures until the end of the 2000's. It means that system seems to be needed for public health research. In fact it seemed that Rwanda alone was not able to develop such research field without this international help.

Our analysis demonstrated that the main field of public health in the 86 records concerned Millenium Development Goal 4 (reduce child mortality), 5 (improve maternal health) and 6 (combat HIV/AIDS, malaria and other diseases) about HIV spread and mother-child transmission, so that new programs were developed to explain this transmission ${ }^{17}$. Moreover, the programs focused on rural provinces ${ }^{3}$. Within the HIV studies, violence and sexual abuse concerning women were putting forward (Millenium Development Goal 5).

Nevertheless, we thought that other subjects could be more represented, such as mental health diseases, after the genocide ${ }^{18}$. This area seems to be dormant and could benefit from renewed impetus and focus on re- search and publishing. It could be that they do the work but do not publish. Research on areas of health systems and Ministry of Health and Family Welfare were not available in our study and could be a limitation. Mental health seemed relevant not only because of war-related trauma, but also of disease-related trauma such as AIDS or other diseases. It seems clear that the current policies are not involved in such a field. Only four records on 86 put forward mental health. Mental health is clearly a burning issue for researchers in neighboring countries as Uganda. The studies deal with the impact of war in psychiatric problems and also with the impact of disease ${ }^{19-20}$. It could be explained by an historical and political points of view. In fact, in order to rebuild the country, the most urgent was not the psychiatric concerns. For the neighboring countries where most victims fled to, such as Uganda, post-traumatic disorders have become an obvious problem to take into account.

Finally, the networks between countries and the funding companies demonstrated that the public health in Rwanda, focused on HIV and mother-child transmission, since 6 years, were funded by Western organization with a major collaboration between Rwanda and the United States of America. Then, Belgium played also a major role, showing that Belgium remains still help for Rwanda. Asian countries were not really implicated in the studies onpublichealth. European countries such as England, Switzerland or France were involved in these records. Other African countries such as Kenya, Ivory Coast, and Ethiopia were also involved. In fact, a limit of our study was the only use of SCIE database. This study was performed on this data base because the analyses were possible with the system. Suchfunctionisnotavailable withother databases. That's why we thought that the participation of other African countries might be under estimated in the Rwandan public health research.

However, the link between the United States and Rwanda in this field, even if a bias of database choic could be seen, seems clearly relevant compared to other links.

\section{Conflicts of interest}

None

\section{References}

1. Poreau B. Extension de la théorie de la reconnaissance, l'exemple du génocide rwandais. Paris:
L'Harmattan, $2011 . \quad$ L'Harmattan, 2012.

. Meessen B, Kashala JPI, Musango L. Outputpayment to boost staff productivity in public health centres: contracting in Kabutare district, Rwanda. Bulletin of the World Health Organization. $2007 ; 85: 198-115$.

3. Meessen B, Kashala JPI, Musango L, Lemlin J. Reviewing institutions of rural health centres: The performance initiative in Butare, Rwanda. Tropical medicine and international health. 2006;11:1303-1317.

4. Leroy V, Newell ML, Dabis F, et al. International multicenter pooled analysis of late postnatal motherto-child transmission of HIV-1 infection. The Lancet. 1998;352:597-600.

5. Zoli A, Shey-Njila, Assana E, et al. Regional status, epidemiology and impact of Taenia solium cysticercosis in Western and Central Africa. Acta Tropica. 2003;87:35-42.

6. Munyandamutsa N, Nkubamugisha PM, Gex-Fabry $\mathrm{M}$, et al. Mental and physical health in Rwanda 14 years after the genocide. Social psychiatry and psychiatric epidemiology. $2012 ; 47: 1753-1761$.

7. Meessen B, Soucat A, Sekabaraga C. Performancebased financing: just a donor fad or a catalyst towards comprehensive health-care reform? Bulletin of the World Health Organization. 2011 ;89:153-156.

8. World Health Organization. Rapport annuel 2011 Kigali: World Health Organization, 2012.

9. Law J, Whittaker J. Mapping acidification research: a test of the co-word method. Scientometrics. 1992;23:417-461.

10.Chiu WT, Huang JS, Ho YS. Bibliometric analysis of severe acute respiratory syndrome related research in the beginning stage. Scientometrics 2004;61:69-77.

11. Jose L. Aleixandre JL, Aleixandre-Tudo JL, Bolanos-Pizzaro M, Aleixandre-Benavent R. Mapping the Scientific Research on Wine and Health (2001-2011). J. Agric. Food Chem.2013;61:11871-11880

12. Mann JM. Medicine and public health, ethics and human rights. Hastings Center report. 1997;27:6-

Otten M, Aregawi M, Were W et al. Initial evidence of reduction of malaria cases and deaths in Rwanda and Ethiopia due to rapid scale-up of malaria prevention and treatment. Malaria Journal. 2009;8.

14. Ettling MB, Shepard DS. Economic cost of malaria in Rwanda. Tropical medicine and parasitology. 1991;42:214-218.

15. Ruxin J, Negin J. Removing the neglect from neglected tropical diseases: Rwandan experience (20082010). Global public health. 2012;7:812-822.
L'Harmattan, 2012. 
17. Binagwaho A, Mugwaneza P, Irakoze A et al. Sclaing up early infant diagnosis of HIV in Rwanda, 20082010. Journal of Public Health Policy. 2012:1-15.

18. Munyandamutsa N, Nkubamugisha P, Gex-Fabry M, Eytan A. Mental and physical health in Rwanda 14 years after the genocide. Soc Psychiatry Psychiatr Epidemiol.,2012;47:1753-1761.

19. Okello J, Nakimuli-Mpungu E, Musisi S, Broekaert E, Derluyn I. The association between mental health symptoms among school-going adolescents in Northern Uganda : the moderating role of war-related trauma. Plos One, 2014;9;e88494.

20. Han CH, Ssewamala FM, Wang J. Family economic empowerment and mental health among AIDS-affected children living in AIDS-impacted communities: evidence from a randomised evaluation in southwerstern Uganda, J Epidemiol Community Health, 2013;67:225-230. 